\title{
PERANAN KUALITAS PELAYANAN, HARGA DAN SUASANA PENGARUHNYA TERHADAP KEPUASAN PELANGGAN BAKSO BOEDJANGAN BINTARA
}

\author{
(THE ROLE OF QUALITY OF SERVICE, PRICE AND ATMOSPHERE \\ EFFECT ON CUSTOMER SATISFACTION BAKSO BOEDJANGAN \\ BINTARA)
}

Oleh:

Rochmad Fadjar Darmanto ${ }^{1)}$; Anik Ariyanti²)

Sekolah Tinggi Ilmu Ekonomi IPWI Jakarta 1,2)

rochmadfadjar@yahoo.co.id1) ariyanti.anik@yahoo.co.id²)

Submit: 03 Apr $2020 \quad$ Review: 17 Apr 2020 Accept: 28 Apr 2020 Publish: 30 Apr 2020

\begin{abstract}
Service quality, price and atmosphere influence customer satisfaction. The purpose of this study was to determine the effect of service quality, price and atmosphere on customer satisfaction at Bakso Boedjangan Bintara. The study population was customers of Bakso Boedjangan Bintara and samples taken by 100 people. The data analysis method of this research is multiple linear regression analysis previously tested with the classic assumption test. The test results show that service quality, price and atmosphere have an effect on customer satisfaction Bakso Boedjangan Bintara.
\end{abstract}

Keywords: Service quality, price and atmosphere influence customer satisfaction

\section{ABSTRAK}

Kualitas pelayanan, harga dan suasana berpengaruh terhadap kepuasan pelanggan. Tujuan penelitian ini adalah untuk mengetahui pengaruh kualitas pelayanan, harga dan suasana terhadap kepuasan pelanggan Bakso Boedjangan Bintara. Populasi penelitian adalah pelanggan Bakso Boedjangan Bintara dan sampel yang diambil sebesar 100 orang. Metode analisis data penelitian ini adalah analisis regresi linier berganda yang sebelumnya diuji dengan uji asumsi klasik, Hasil pengujian menunjukkan bahwa kualitas pelayanan, harga dan suasana berpengaruh terhadap kepuasan pelanggan Bakso Boedjangan Bintara.

Kata kunci: Kualitas pelayanan, harga dan suasana berpengaruh terhadap kepuasan pelanggan 


\section{PENDAHULUAN}

Bakso adalah makanan yang paling digemari oleh masyarakat Indonesia, baik dari kalangan menengah ke bawah maupun menengah ke atas, baik masyarakat yang tinggal di desa maupun yang tinggal di perkotaan. Hampir di setiap jalanan, perumahan, perkantoran dan tempat-tempat umum, kumpulan pedagang kaki lima, dan tempat-tempat kuliner, tempat hiburan, tempat rekreasi dan pasar-pasar, pasti kita jumpai pedagang bakso baik dijual dengan gerobak atau warung/kedai, bahkan di sumpermarket. Hal ini menunjukkan bahwa bakso menjadi makanan favorit masyarakat Indonesia. Bakso sebenarnya bukan makanan yang berasal dari Indonesia, tetapi berasal dari negara China, seperti diungkapkan Primadia (2017).

Dalam sejarahnya, bakso yang dikenal saat ini diperkenalkan oleh pedagang China yang menetap di Indonesia. keberadaan bakso diawali pada akhir Dinasti Ming di Fuzhou sekitar awal abad ke-17. Adalah seorang anak bernama Meng Bo yang baik hati, membantu ibunya yang sudah tua dengan gigi yang rapuk agar tetap bisa memakan daging kesukaannya yaitu dengan daging tumbuk dan dibuat seperti mochi, yang kebetulan terinspirasi tetangganya membuat mochi. Daging tumbuk dalam bentuk bulatan tersebut direbus dan disajikan dengan kaldu dagingnya dengan aroma yang sedap. Cerita bakti Meng Bo dan baksonya ini menyebar luas ke seluruh kota Fuzhou dan sampai akhirnya sampai ke wilayah Indonesia seperti yang kita kenal saat ini. Kata "bakso" berasal dari kata Bak dan So. Kata "bak" berarti daging babi dan "so" berarti kuah. Sehingga "bakso berarti kuah dengan daging babi". Tetapi setelah memasuki wilayah Indonesia, daging babi diganti dengan daging lainnya seperti daging sapi, ayam, dan ikan (seafood). Dalam bahasa Hokkien yang secara harafiah Bak-So berarti "daging giling"(Primadia, 2017).

Pemilik "Bakso Boedjangan" menangkap peluang itu, dengan membuka rumah makan di kota Bandung Jawa Barat pada 9 Januari 2015 dengan sebuah manajemen yang bekerjasama dengan Upnormal dan Nasi Goreng Mafia. Perkembangan selanjutnya "Bakso Boedjangan" tidak hanya ada di kota Bandung tetapi sudah meluas ke beberapa daerah Jabodetabek dan kota-kota lain di Indonesia dengan jumlah restoran/gerai sampai dengan tahun 2019 adalah 61 cabang. Hal ini sejalan dengan visi dan misinya yaitu menjadi perusahaan kuliner dengan outlet tersebar di seluruh dunia dengan tetap memiliki cita rasa tinggi, membangun organisasi yang profesional dan inovatif serta membangun dan terus mengembangkan pabrik produksi (CRP Group, 2019).

Peneliti mengamati bahwa "Bakso Boedjangan" ini mempunyai keunggulan selain nama sudah menjadi "hit", gerainya asik, full wifi, dan menu baksonya yang unik. Bakso Boedjangan memiliki menumenu paket mie, sayur, bakso besar (bisa urat, keji, atau cengek), bakso goreng dan 3 bakso halus. Selain itu tersedia menu minuman segar. Semua ini menjadi kekhasan dari "Bakso Boedjangan". Bakso Boedjangan mempunyai konsep yang berbeda yaitu pelanggan bisa langsung memilih sendiri bakso yang diinginkannya, disuguhkan pada tempat terbuka namun hiegienis. Dengan konsep yang berbeda tersebutlah yang menarik minat pelanggan khususnya. Setiap hari pengunjungnya banyak dan selalu dengan anteran yang panjang. Rata-rata 
pengunjungnya lebih dari 100 orang per harinya, dibuktikan dari kapasitas tempat duduknya berjumlah lebih dari 100 dan selalu penuh (Duta.co/wiwik, 2019).

$$
\text { Bakso Boedjangan Bintara }
$$

memaksimalkan pelayanan dengan berupaya memenuhi kebutuhan para pelanggannya. Bentuk pelayanan yang diberikan adalah ketepatan waktu pelayanan, akurasi pelayanan, sopan santun, kemudahan dan membuat pelanggan nyaman.

Tjiptono (2016) menjelaskan bahwa pelayanan yang berkualitas adalah upaya memenuhi kebutuhan yang dibarengi dengan keinginan konsumen serta ketepatan cara penyampaiannya agar dapat memenuhi harapan dan kepuasan pelanggan tersebut.

Selain kualitas pelayanan, harga juga menjadi faktor yang mempengaruhi kepuasan pelanggan. Harga merupakan merupakan aspek yang tampak jelas bagi pelanggan dan harga dijadikan indikator dari kualitas pelayanan. Besar kecilnya harga mempengaruhi kualitas produk yang dibeli oleh pelanggan. Keputusan mengenai harga dipengaruhi oleh faktor internal dan eksternal lingkungan (Kotler dan Amstrong, 2015).

Tidak hanya kualitas pelayanan dan harga, faktor yang tidak kalah penting untuk meningkatkan kepuasan pelanggan adalah suasana (atmosphere) di lingkungan toko/gerai/rumah makan. Store atmosphere yang meliputi exterior, general interior, store layout dan interior displays memberikan pengaruh terhadap kepuasan konsumen atau pelanggan. Store Atmosphere berpengaruh positif terhadap kepuasan konsumen (Widyandani, 2017).

Mengacu pada pendapat para peneliti tersebut maka penelitian ini akan mengupas tentang pengaruh kualitas pelayanan, harga dan suasana terhadap kepuasan pelanggan "Bakso Boedjangan
Bintara" yang berlokasi di Jalan Bintara Raya Kota Bekasi.

\section{TUJUAN PENELITIAN}

Penelitian ini bertujuan untuk mengetahui pengaruh kualitas pelayanan, harga dan suasana terhadap kepuasan pelanggan Bakso Boedjangan Bintara.

\section{TELAAH LITERATUR DAN PENGEMBANGAN HIPOTESIS Kepuasan Pelanggan}

Kepuasan pelanggan merupakan tolok ukur untuk melihat kualitas pelayanan yang diberikan kepada pelanggan. Kepuasan pelanggan lebih mengarah pada perasaan senang atau kecewa dari seseorang yang muncul setelah membandingkan produk maupun jasa dari apa yang mereka pikirkan dengan apa yang diharapkan. Pelanggan yang merasa puas akan mempertahankan loyalitasnya terhadap produk atau jasa yang didapat sehingga akan memberikan dampak pada hasil penjualan (Kotler dan Keller, 2014).

Kepuasan pelanggan lebih pada konsumen yang merasa puas terhadap suatu merek atau produk yang dikonsumsinya dan akan membeli ulang produk tersebut (Suwarman, 2015). Beberapa faktor yang mempengaruhi kepuasan pelanggan adalah mutu produk, penetapan harga, pengalaman belanja yang menyenangkan, testimoni orang lain, dan strategi pemasaran seperti dijelaskan dalam artikel (Sodexo, 2019).

\section{Pengaruh Kualitas Pelayanan terhadap Kepuasan Pelanggan}

Kualitas pelayanan adalah tingkat keunggulan menjadi harapan dan pengendalian pada tingkat keunggulan tersebut dalam memenuhi keinginan pelanggan. Faktor yang mempengaruhi 
layanan adalah expected service dan perceived service atau layanan yang diharapkan dan layanan yang diterima. Apabila layanan yang diterima sesuai dan memenuhi harapan maka jasa tersebut masuk kategori baik dan positif (Tjiptono, 2016).

Kualitas pelayanan memiliki hubungan yang erat dengan kepuasan konsumen. Kualitas pelayanan memberikan dorongan kepada konsumen untuk menjalin ikatan dan hubungan yang kuat dengan konsumen (Safrizal, 2015).

Pada penelitian lain disebutkan bahwa terdapat pengaruh kualitas pelayanan terhadap kepuasan konsumen (Muslikah dan Gunawan, 2017). Pendapat ini dikuatkan penelitian Sulistyawati (2015) bahwa kualitas pelayanan adalah faktor penting dan mampu memberikan kepuasan terhadap pelanggan. Pelanggan akan merasa puas dengan adanya pelayanan yang diberikan. Kualitas pelayanan yang meliputi keandalan, daya tanggap, jaminan, empati, dan perbedaan gender berpengaruh terhadap kepuasan pelanggan.

Penelitian lainnya menjelaskan bahwa faktor yang berpengaruh terhadap kepuasan pelanggan adalah responsiveness atau daya tanggap, yang diikuti oleh assurance, emphaty, tangible dan realiability (Sasongko dan Subagio, 2013).

Berdasarkan teori dan uraian di atas, maka disimpulkan hipotesis sebagai berikut:

H1: Kualitas pelayanan berpengaruh terhadap kepuasan pelanggan

\section{Pengaruh Harga terhadap Kepuasan Pelanggan}

Kotler dan Amstrong (2015:312) berpendapat: "Prince the amount of money charged for a product or service, or the sum of the value that customers exchange for the benefits or having or using the product or service" atau harga adalah jumlah uang yang dengan sengaja dikeluarkan untuk sebuah produk atau jasa. Atau dalam arti lain harga adalah nilai dalam jumlah tertentu yang ditukarkan konsumen untuk mendapatkan manfaat kepemilikan atau penggunaan sebuah produk dan/atau jasa sesuai dengan keinginan. Dengan demikian harga adalah nilai suatu barang yang dinyatakan dengan senilai uang.

Kotler dan Amstrong menjelaskan indikator harga meliputi keterjangkauan harga, kesesuaian harga dengan kualitas produk, daya saing harga dan kesesuaian harga dengan manfaat (Sabran, 2012:278). Penelitian terdahulu menyebutkan bahwa harga berpengaruh signifikan terhadap kepuasan pelanggan. Artinya bahwa harga yang ditawarkan murah terjangkau dan rasanya tidak kalah dengan rumah makan yang lain, ternyata mempengaruhi kepuasan pelanggan (Wahyudi, 2018). Pendapat ini diperkuat oleh Nurmasari, Miftah El Fikri dkk (2018) yang menjelaskan bahwa harga berpengaruh terhadap kepuasan pelanggan.

Harga berpengaruh terhadap kepuasan konsumen pada rumah makan. Rata-rata konsumen memberikan respon positif pada harga yang ditawarkan oleh rumah makan (Devi, Suharyono, dan Dahlan (2017).

Berdasarkan teori dan uraian di atas, maka disimpulkan hipotesis sebagai berikut:

H2: Harga berpengaruh terhadap kepuasan pelanggan.

\section{Pengaruh Suasana terhadap Kepuasan Pelanggan}

Levy dan Weifz mengatakan suasana (atmosphere) adalah tatanan yang didesain khusus melalui visual, pencahayaan, seni dan musik dan aroma untuk menciptakan 
lingkungan yang nyaman pelanggan (Dian \& Artanti, 2013: 416).

Indikator suasana adalah meliputi: 1) pengaturan di dalam ruangan yang menyangkut internal layout, suara, bau atau aroma, tampilan fisik, desain interior. 2) Outstore Atmosphere atau pengaturan di luar ruangan yang menyangkut external layout, tampilan fisik, design eksterior. (Harianto dan Sugiono, 2013:3)

Suasana merupakan komponen penting dari rumah makan dan bisa memberikan efek sensorik atau menarik konsumen untuk datang ke rumah makan. Dalam penelitian disebutkan bahwa suasana atau atmosphere sebuah restoran berperan penting dalam mempengaruhi kepuasan pelanggan (Widyandani, 2017).

Penelitian lain mengatakan bahwa store atmosphere secara parsial berpengaruh terhadap kepuasan konsumen. Semakin tinggi store atmosphere yang dilakukan oleh toko/rumah makan maka akan meningkatkan kepuasan konsumen dengan cepat.

Penciptakan suasana (atmosphere) yang nyaman dan sesuai dengan selera pelanggan akan berpengaruh terhadap kepuasan pelanggan. Dengan pajangan yang menarik, aroma dan musik yang nyaman serta faktor pencahayaan yang baik akan meningkatkan kepuasan pelanggan (Masrul \& Karneli, 2017). Pendapat lain mengatakan bahwa store atmosphere mempunyai pengaruh terhadap kepuasan pelanggan (Kristina dan Edwar, 2017).

Berdasarkan teori dan uraian di atas, maka disimpulkan hipotesis sebagai berikut:

H3: Suasana berpengaruh terhadap kepuasan pelanggan.

Beberapa uraian di atas memberikan kerangka pemikiran, sebagai berikut:
Gambar 1

Kerangka Pemikiran

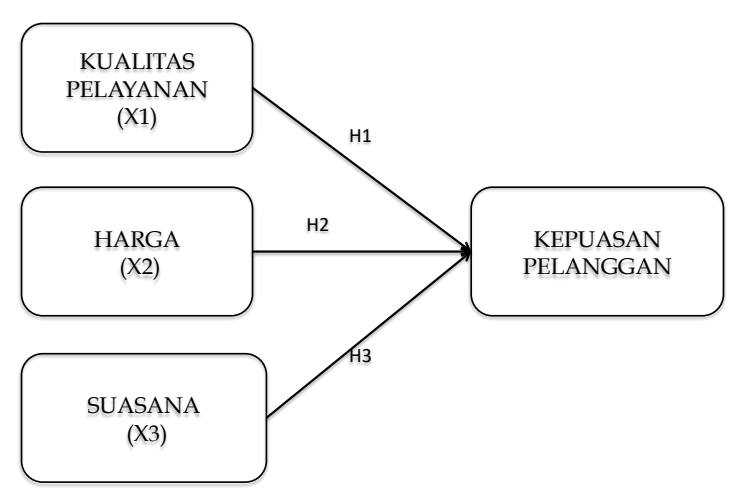

\section{METODE PENELITIAN Variabel Penelitian}

Variabel dalam penelitian ini terdiri atas variabel dependen dan variabel independen. Variabel dependen adalah kualitas pelayanan, harga dan suasana dan variabel independen adalah kepuasan pelanggan.

Tabel 1

Variabel dan Indikator

\begin{tabular}{|l|l|l|}
\hline \multicolumn{1}{|c|}{ Variabel } & \multicolumn{1}{|c|}{ Definisi } & \multicolumn{1}{c|}{ Indikator } \\
\hline $\begin{array}{l}\text { Kualitas } \\
\text { Pelayanan } \\
\left(\mathrm{X}_{1}\right)\end{array}$ & $\begin{array}{l}\text { Kualitas pelayanan } \\
\text { adalah tingkat } \\
\text { keunggulan yang } \\
\text { diharapkan dan } \\
\text { pengendalian atas } \\
\text { tingkat keunggulan } \\
\text { tersebut untuk } \\
\text { memenuhi keinginan } \\
\text { pelanggan. } \\
\text { (Tjiptono, 2016) }\end{array}$ & $\begin{array}{l}\text {-Reliability } \\
\text {-Responsiveness } \\
\text {-Assurance } \\
\text {-Empathy }\end{array}$ \\
& $\begin{array}{l}\text {-Tangible } \\
\text { (Parasuraman } \\
\text { dalam Tjiptono, } \\
\text { 2016) } \\
\text { uanga adalah jumlah } \\
\text { dikeluarkan untuk } \\
\text { sebuah produk atau } \\
\text { jasa. (Kotler dan } \\
\text { Amstrong, 2015) }\end{array}$ & $\begin{array}{l}\text { - Keterjangkauan } \\
\text { harga } \\
\text {-kesesuaian harga } \\
\text { dengan produk } \\
\text { daya saing harga } \\
\text { dan kesesuaian } \\
\text { harga dengan }\end{array}$ \\
& $\begin{array}{l}\text { manfaat. } \\
\text { (Kotler dan }\end{array}$ \\
& $\begin{array}{l}\text { Amstrong dalam } \\
\text { Sabran, 2012) }\end{array}$ \\
\hline
\end{tabular}




\begin{tabular}{|c|c|c|}
\hline Variabel & Definisi & Indikator \\
\hline Suasana $\left(X_{3}\right)$ & $\begin{array}{l}\text { Suasana (atmosphere) } \\
\text { adalah tatanan yang } \\
\text { didesain khusus } \\
\text { melalui visual, } \\
\text { pencahayaan, seni dan } \\
\text { musik danaroma untuk } \\
\text { menciptakan } \\
\text { lingkungan yang } \\
\text { nyaman bagi pelanggan } \\
\text { (Levy dan Weitz dalam } \\
\text { Dian \& Artanti, 2013) }\end{array}$ & $\begin{array}{l}\text { - Pengaturan di } \\
\text { dalam ruangan } \\
\text { (interior layout) } \\
\text { - Pengaturan di } \\
\text { dalam atau } \\
\text { outstore } \\
\text { atmosphere. } \\
\text { (Levy dan Weitz } \\
\text { dalam Harianto \& } \\
\text { Subagio, 2013) }\end{array}$ \\
\hline $\begin{array}{l}\text { Kepuasan } \\
\text { Pelanggan } \\
(Y)\end{array}$ & \begin{tabular}{|l} 
Kepuasan pelanggan \\
adalah konsumen \\
merasa puas terhadap \\
suatu merek atau \\
produk yang \\
dikonsumsinya dan \\
akan kembali membali \\
ulang produk tersebut \\
(Suwarman, 2015)
\end{tabular} & $\begin{array}{l}\text { - Merasa puas } \\
\text { - merasa senang } \\
\text { - tidak ada keluhan } \\
\text { (Putri, 2015) } \\
\text { - Penetapan harga } \\
\text { - Pengalaman } \\
\text { belanja yang } \\
\text { menyenangkan } \\
\text { - Testimoni } \\
\text { - Strategi } \\
\text { pemasaran } \\
\text { (Sodexo.co.id) }\end{array}$ \\
\hline
\end{tabular}

Sumber: Kajian Literatur

\section{Populasi dan Sampel}

Ferdinand (2014) menjelaskan bahwa populasi adalah percampuran semua elemen seperti peristiwa, hal atau manusia dengan ciri sejenis sehingga menjadi pusat perhatian peneliti karena sebagai semesta penelitian. Populasi penelitian ini adalah seluruh pelanggan pada Bakso Boedjangan Bintara yang telah melakukan pembelian pada tahun 2018 sampai dengan 2019 sebanyak 11.000 orang.

Teknik pengambilan sampel pada penelitian ini menggunakan probability sampling dengan kategori simple random sampling. Pengambilan sampel ditentukan secara acak tanpa memperhatikan strata yang ada dalam populasi sehingga semua pelanggan Bakso Boedjangan Bintara memiliki kesempatan yang sama.

Sugiyono (2017) mengatakan bahwa sampel adalah bagian dari jumlah dan ciri yang dimiliki oleh populasi. Pemilihan sampel berdasarkan Rumus Slovin, adalah sebagai berikut:
Keterangan:

$$
n=\frac{N}{1+N \cdot e^{2}}
$$

$$
\begin{array}{ll}
\mathrm{n} & =\text { Jumlah Sampel } \\
\mathrm{N} & =\text { Jumlah Populasi } \\
\mathrm{e} & =\text { Presentasi Toleransi 10\% }
\end{array}
$$

Husein Umar (2008: 67)

Perhitungan sampel sebagai berikut:

$$
\begin{gathered}
n=\frac{11.000}{1+\left(11.000 \times 0,1^{2}\right)} \\
n=\frac{11.000}{110,01} \\
n=99,9 \text { atau } 100 \\
11.000
\end{gathered}
$$

Dari hasil perhitungan di atas, menentukan jumlah sampel penelitian ini minimal 100 orang responden yaitu pelanggan yang membeli Bakso Boedjangan Bintara. Jumlah sampel penelitian ini 100 orang responden yaitu pelanggan yang membeli Bakso Boedjangan Bintara.

\section{Metode Analisis Data}

Metode analisis data dalam penelitian ini menggunakan analisis statistik deskriptif dengan menganalisis dan mendeskripsikan data untuk mengetahui nilai variabel independen dan dependen, yaitu dengan menghitung nilai rata-rata. Dan untuk mengetahui kelayakan model regresi dilakukan uji asumsi klasik yang terdiri dari uji normalitas, uji heteroskedastisitas, uji multikolinearitas. Menguji analisis regresi berganda dengan menilai koefisien determinasi dan melakukan pengujian hipotesis dengan uji $\mathrm{t}$ dan uji $\mathrm{F}$. 
HASIL PENELITIAN \& PEMBAHASAN Hasil Penelitian

\section{Uji Validitas dan Reliabilitas}

Setelah melakukan pengujian validitas dan reliabilitas dapat diketahui bahwa hasil kuesioner yang disebarkan menunjukan masing-masing variabel yaitu kualitas pelayanan, harga, suasana dan kepuasan pelanggan dapat disimpulkan valid dan dalam kategori data yang reliabel.

\section{Deskripsi Hasil Penelitian}

Pada hasil deskriptif statistik diketahui bahwa nilai rata-rata jawaban responden untuk masing-masing variabel termasuk pada kategori cukup baik. Hal ini dibuktikan pada skor tertinggi teoritik atas 10 pernyataan dengan skala dari 1-5 adalah tertinggi 100 dan terendah 10 , dengan nilai tengah 50. Nilai rata-rata empirik (mean) lebih kecil daripada nilai tengah teoritik (kualitas pelayanan sebesar 38,04, harga sebesar 36,45 , suasana sebesar 36,15 , dan kepuasan pelanggan sebesar 34,98 artinya $<50)$. Hal ini mengindikasikan nilai ratarata jawaban untuk semua variabel adalah cukup baik.

\section{Uji Asumsi Klasik}

Hasil uji multikolinieritas diketahui adalah sebesar $0,859 \quad\left(X_{1}\right), \quad 0,898 \quad\left(X_{2}\right)$, $0,952\left(X_{3}\right)$ menunjukkan nilai lebih dari atau $>10 \%$. Variance Inflation Factor (VIF) untuk masing-masing variabel independen lebih kecil $<$ VIF $=10$ artinya antara variabel independen tidak terjadi multikolinieritas.

Hasil uji heteroskedastisitas, pada grafik Scatterplot menunjukkan terpenuhinya heteroskedastisitas dimana tidak ada ditemukannya pola yang jelas dan terlihat titik-titik menyebar secara acak dan tidak membentuk pola tertentu, seperti pada gambar berikut:
Gambar 2

Uji Heteroskedastisitas

scatterpiot

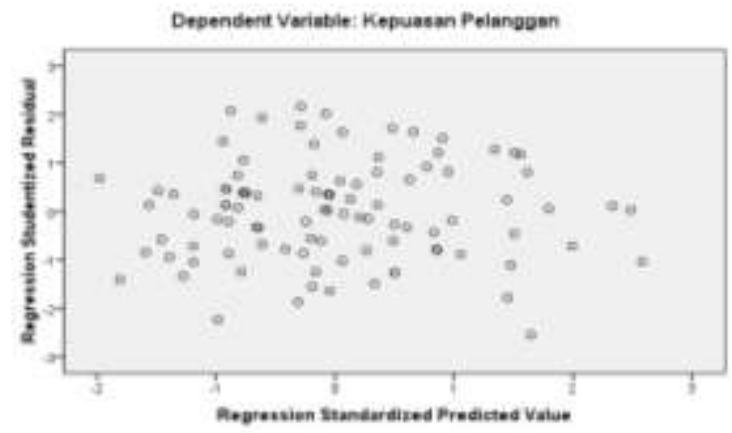

Sumber: SPSS

Hasil uji normalitas diketahui bahwa grafik P-Plot, sebagai berikut:

Gambar 3

Normal P-Plot Uji Normalitas

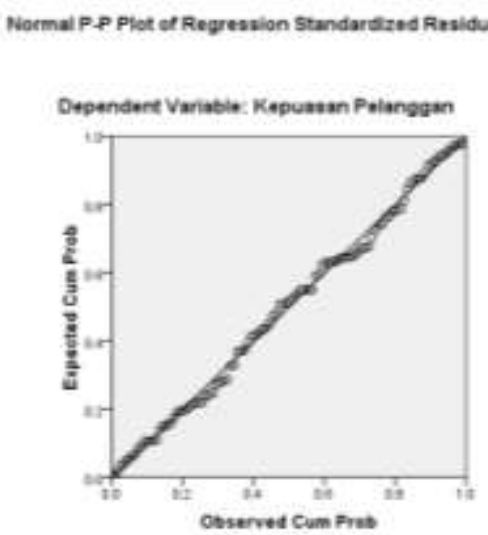

Sumber: SPSS

\section{Koefisien Determinasi}

Model pengaruh kualitas pelayanan, harga dan suasana terhadap kepuasan pelanggan adalah sebagai berikut:

Tabel 2

Koefisien Determinasi

\begin{tabular}{|l|r|r|r|r|}
\hline Model & \multicolumn{1}{|c|}{$\mathrm{R}$} & R Square & $\begin{array}{c}\text { Adjusted R } \\
\text { Square }\end{array}$ & $\begin{array}{c}\text { Std. Error } \\
\text { of the } \\
\text { Estimate }\end{array}$ \\
\hline 1 & $.456^{\mathrm{a}}$ & .208 & .183 & 3.091 \\
\hline
\end{tabular}

Sumber: SPSS 
Tabel 2 membuktikan bahwa nilai koefisien determinasi pada Adjusted $R$ Square sebesar 0,183 atau $18,3 \%$ menunjukkan bahwa kualitas pelayanan, harga dan sarana mempengaruhi kepuasan pelanggan, sedangkan $81,8 \%$ dari faktor lain yang tidak diteliti.

\section{Tabel 3 \\ Uji F \\ ANOVA $^{\mathrm{b}}$}

\begin{tabular}{|l|r|r|r|r|r|}
\hline Model & $\begin{array}{r}\text { Sum of } \\
\text { Squares }\end{array}$ & df & $\begin{array}{c}\text { Mean } \\
\text { Square }\end{array}$ & F & Sig. \\
\hline 1 Regression & 240.896 & 3 & 80.299 & 8.407 & $.000^{a}$ \\
Residual & 916.944 & 96 & 9.552 & & \\
Total & 1157.840 & 99 & & & \\
\hline
\end{tabular}

a. Predictors: (Constant), Suasana, Harga, Kuali

b. Dependent Variable: Kepuasan Pelanggan

Sumber: SPSS

Tabel di atas menunjukkan bahwa nilai $\mathrm{F}$ hitung sebesar 8,407 dengan nilai sig sebesar 0,000 sehingga dapat disimpulkan bahwa nilai sig $0,000<0,05$, artinya kualitas pelayanan, harga dan suasana berpengaruh signifikan terhadap kepuasan pelanggan Bakso Boedjangan Bintara.

\section{Pengujian Hipotesis}

Pada hasil pengujian dapat diketahui nilai sebagai berikut:

$Y=17,314+0,195 X_{1}+0,232 X_{2}+0,149 X_{3}$.

Nilai ini menjelaskan bahwa konstanta kepuasan pelanggan (Y) sebesar 17,314, jika nilai kualitas pelayanan $\left(X_{1}\right)$, harga $\left(X_{2}\right)$ dan suasana $\left(X_{3}\right)$ nilainya adalah 0 .

Pengaruh kualitas pelayanan terhadap kepuasan pelanggan ditunjukkan pada nilai koefisien regresi b1 sebesar 0,195 yang memiliki nilai sig sebesar $0,022<0,05$; artinya kualitas pelayanan berpengaruh signifikan terhadap kepuasan pelanggan Bakso Boedjangan Bintara.

Pengaruh harga terhadap kepuasan pelanggan ditunjukkan pada nilai koefisien regresi b2 sebesar 0,232 yang memiliki nilai sig sebesar $0,016<0,05$; artinya harga berpengaruh signifikan terhadap kepuasan pelanggan Bakso Boedjangan Bintara.

Pengaruh suasana terhadap kepuasan pelanggan ditunjukkan pada nilai koefisien regresi b3 sebesar 0,149 yang memiliki nilai sig sebesar $0,024<0,05$; artinya suasana berpengaruh signifikan terhadap kepuasan pelanggan Bakso Boedjangan Bintara.

Semua hasil di atas lebih jelasnya seperti pada tabel berikut:

Tabel 4

Koefisien Regresi

\begin{tabular}{|c|c|c|c|c|c|}
\hline \multirow[b]{2}{*}{ Model } & \multicolumn{2}{|c|}{$\begin{array}{l}\text { Unstandardize } \\
\text { d Coefficients }\end{array}$} & \multirow{2}{*}{ 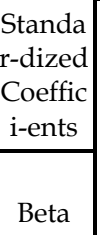 } & \multirow[b]{2}{*}{$\mathrm{t}$} & \multirow[b]{2}{*}{ Sig. } \\
\hline & B & $\begin{array}{l}\text { Std. } \\
\text { Error }\end{array}$ & & & \\
\hline 1 (Constant) & 17.314 & 4.188 & & 4.134 & .000 \\
\hline $\begin{array}{l}\text { Kualitas } \\
\text { Pelayanan }\end{array}$ & .195 & .084 & .228 & 2.328 & .022 \\
\hline Harga & .232 & .094 & .236 & 2.461 & .016 \\
\hline Suasana & .149 & .065 & .213 & 2.291 & .024 \\
\hline
\end{tabular}

Sumber: SPSS

\section{Pembahasan}

Pengaruh Kualitas Pelayanan terhadap Kepuasan Pelanggan

Kualitas pelayanan berpengaruh terhadap kepuasan pelanggan Bakso Boedjangan Bintara. Jika kualitas pelayanan Bakso Boedjangan Bintara ditingkatkan maka akan berpengaruh terhadap kepuasan pelanggan. Hal ini sependapat dengan penelitian Krisdianti (2019) dalam penelitiannya bahwa kualitas pelayanan terutama empati mempunyai pengaruh yang besar terhadap kepuasan konsumen. Pendapat lain menjelaskan bahwa kualitas pelayanan adalah mutu dari pelayanan yang diberikan kepada pelanggan, baik pelanggan internal maupun pelanggan eksternal berdasarkan prosedur pelayanan (Suwithi dan Anwar, 2013:84). Hal ini sependapat dengan 
penelitian Situmeang (2017) bahwa kualitas pelayanan berpengaruh terhadap kepuasan konsumen.

Pelayanan dikatakan berkualitas apabila mampu menyediakan produk ataupun jasa yang sesuai dengan keinginan, kebutuhan dan harapan pelanggan. Tujuan paling utama dalam memberikan kualitas pelayanan adalah untuk tetap terjalin hubungan yang baik dengan para pelanggan dengan harapan loyalitas pelanggan akan tetap terjaga. Bahwa kualitas pelayanan terutama pada faktor daya tanggap mempunyai pengaruh yang dominan terhadap kepuasan konsumen (Apriyani, 2017).

\section{Pengaruh Harga terhadap Kepuasan Pelanggan}

Harga berpengaruh terhadap kepuasan pelanggan Bakso Boedjangan Bintara. Penetapan harga yang sesuai dengan keinginan dan kebutuhan pelanggan akan berpengaruh terhadap kepuasan pelanggan pada Bakso Boedjangan Bintara. Dalam Wikipedia dijelaskan bahwa harga adalah suatu nilai tugas yang berupa uang atau barang lain untuk manfaat yang diperoleh dari barang atau jasa bagi individu atau kelompok pada waktu dan tempat tertentu. Harga merupakan alat penentu keberhasilan sebuah perusahaan dalam menjalankan usahanya. Penetapan suatu harga barang bertujuan untuk menentukan pangsa pasar, meningkatkan keuntungan, menjaga loyalitas konsumen dan menjaga daya saing antar kompetitor.

Harga menentukan kepuasan konsumen dan harga yang sesuai sangat berpengaruh positif terhadap kepuasan konsumen. Semakin terjangkau dan sesuai dengan harapan maka harga akan semakin kuat mempengaruhi kepuasan konsumen (Wijaya, 2017).

\section{Pengaruh Suasana terhadap Kepuasan Pelanggan}

Suasana (atmosphere) berpengaruh terhadap kepuasan pelanggan Bakso Boedjangan Bintara. Peningkatan dan perubahan suasana (atmosphere) yang menarik dan sesuai dengan kesukaan pelanggan akan berpengaruh terhadap kepuasan pelanggan Bakso Boedjangan Bintara. Hal ini sependapat dengan penelitian yang dilakukan oleh Devi, Suharyono, dan Dahlan (2017) bahwa store atmosphere berpengaruh terhadap kepuasan konsumen. Suasana restoran baik interior, eksterior, store layout, dan interior displays sangat mempengaruhi suasana hati pelanggan. Elemen-elemen tersebut merupakan daya tarik yang harus ditonjolkan untuk memikat pelanggan untuk berkunjung, bertahan lama di tempat (karena merasa nyaman) dan mengasyikan. Seorang konsumen ketika masuk ke sebuah toko/restoran mereka tidak hanya memberikan kesan pada produk dan harga yang ditawarkan, tetapi juga respon terhadap lingkungan yang diciptakan toko/restoran tersebut. Kotler dan Amstrong (2016) mengatakan bahwa store atmosphere (suasana toko) adalah alat komunikasi pemasaran yang didesain sedemikian rupa agar bisa memenuhi kebutuhan dan keinginan konsumen. Agar tidak membosankan suasana toko harus dirancang dan didesain semenarik mungkin.

\section{KESIMPULAN}

Kesimpulan dari penelitian ini adalah sebagai berikut:

a. Kualitas pelayanan berpengaruh terhadap kepuasan pelanggan Bakso Boedjangan Bintara, maka semakin berkualitas pelayanan yang diberikan maka kepuasan pelanggan akan lebih meningkat. 
b. Harga berpengaruh terhadap kepuasan pelanggan Bakso Boedjangan Bintara. Artinya penetapan harga yang sesuai dengan keinginan dan kebutuhan pelanggan akan mampu meningkatkan kepuasan pelanggan Bakso Boedjangan Bintara.

c. Suasana (atmosphere) berpengaruh terhadap kepuasan pelanggan Bakso Boedjangan Bintara. Artinya untuk lebih meningkatkan kepuasan pelanggan, maka suasana di lingkungan harus diperhatikan dan dibuat semenarik mungkin.

\section{SARAN}

d. Bakso Boedjangan harus tetap berupaya untuk meningkatkan kualitas pelayanan agar mampu memberikan kepuasan terhadap pelanggannya. Perlu meningkatkan kehandalan, daya tanggap, jaminan/kepastian, empati dan bukti fisik yang bisa ditunjukkan kepada para pelanggan.

b. Harga menjadi faktor yang dominan mempengaruhi kepuasan pelanggan Bakso Boedjangan Bintara. Penetapan harga yang sesuai keinginan dan kebutuhan pelanggan harus menjadi prioritas utama agar pelanggan puas dengan harga yang ditawarkan. Perlu memperhatikan keterjangkaun harga, kesesuaian harga dengan produk, daya saing, dan kesesuaian harga dengan manfaatnya.

c. Suasana yang ditampilkan restoran Bakso Boedjangan Bintara cukup memikat pelanggan bahkan berpengaruh terhadap kepuasan pelanggan. Agar tidak membosankan, suasana restoran terus dirancang dan didesain menarik dalam bentuk komunikasi visual disesuaikan dengan keinginan pelanggan dan terus melakukan inovasi.

\section{DAFTAR PUSTAKA}

Apriyani, Dwi Aliyyah. (2017) "Pengaruh Kualitas Pelayanan terhadap Kepuasan Konsumen The Little A Coffee Shop di Kota Sidoarjo". Tesis. Universitas Brawijaya Malang http://repository.ub.ac.id/id/eprint

CRP Group. (2019). 50 Gerai Bakso Boedjangan dalam 4 Tahun, lebih dari 10 Kota di Indonesia, https://www.citarasaprima.com/post diakses 9 Juli 2019.

Devi, Santika, Suharyono dan Dahlan Fanani. (2017). "Pengaruh Store Atmosphere dan Kualitas Produk terhadap Kepuasan Pelanggan (Survei pada Pelanggan Cafe OTW Food Street Malang". Jurnal Administrasi Bisnis Unibra Malang. http://administrasibisnis.studentjourn al.ub.ac.id/index.php

Dian, Nova Farah dan Yessy Artanti. (2013). Pengaruh Kelompok Acuan dan Atmosfir Restoran terhadap Keputusan Pembelian Konsumen Starbuck Coffee. Jurnal Administrasi Bisnis (JAB) Vol.52 No.1 November 2017. Unesa Surabaya. https://jurnalmahasiswa.unisa.ac.id

Duta.Co/Wiwik. (2019). Strategi Bakso Boedjangan, Terus Inovasi Sesuai Permintaan Pasar. https://duta.co/strategi-baksoboedjangan diakses 4 Juli 2019.

Ferdinand, A. (2014). Metode Penelitian Manajemen: Pedoman Penelitian untuk Skripsi, Tesis dan Disertasi IImu Manajemen. Semarang: Universitas Diponegaro

Harianto, David dan Hartono Subagio. (2013). Analisa Pengaruh Kualitas Pelayanan, Brand Image, dan Atmosphere terhadap Loyalitas Konsumen dengan Kepuasan Konsumen sebagai Variabel Intervening Konsumen Kedai Deja-vu Surabaya. Jurnal Manajemen 
Pemasaran Vol.1 No.1 2013. Universitas Kristen Petra Surabaya. https://media.neliti.com

Kotler, Philip dan Amstrong. (2015). Marketing an Introducing. Prentice Hall twelfth edition. England: Pearson Education, Inc.

Kotler, Philip dan Amstrong. (2016). Marketing Management. 15e, Boston, Pearson Education.

Krisdianti, Dika Lambang dan Sunarti. (2019). Pengaruh Kualitas Pelayanan terhadap Kepuasan Konsumen pada Restoran Pizza Hut Malang Town Square. Jurnal Administrasi Bisnis Vol.70 No.1 2019. http://administrasibisnis.studentjourn al.ub.ac.id

Kristina, Maria dan Muhammad Edwar. (2017). Pengaruh Store Atmosphere dan Kualitas Layanan terhadap Kepuasan Konsumen Cafe Heerlijk Gelato Perpustakaan Bank Indonesia Surabaya. Jurnal Pendidikan Tata Niaga Vol.1 No.1 2017. Unesa Surabaya.

https://jurnalmahasiswa.unesa.ac.id

Masrul dan Okta Karneli. (2017). Pengaruh Store Atmosphere dan Store Location terhadap Kepuasan Konsumen (Studi pada Konsumen Produk Texas Chicken Plaza Citra Pekanbaru. Jurnal. JOM FISIP Vol.4.2 Oktober 2017. Universitas Riau.

Muslikah, Ani dan Yoyo Indah Gunawan. (2017). Pengaruh Kualitas Pelayanan dan Kebijakan Harga terhadap Kepuasan Konsumen PT. HLS Yamaha Music Pejaten Village Mall Jakarta Selatan. Jurnal Pengembangan Wiraswasta. Vol.19 No.3 Desember 2017. STIE IPWI Jakarta: http://ejurnal.stieipwija.ac.id/index.p hp/jpw

Nurmasari, Dewi dan Miftah El Fikri. (2018). Pengaruh Harga dan Kualitas Pelayanan terhadap Kepuasan Pelanggan pada Rumah Makan Sidempuan Medan. Jurnal Manajemen Tools Univ. Pembangunan Panca Budi Medan. http://jurnal.pancabudi.ac.id/index. php/JUMANT/index

Primadia, Adara. (2017). Sejarah Bakso. Sejarah Lengkap.com. https://sejarahlengkap.com/indonesi a/sejarah-bakso/attachmen diakses pada 6 Juni 2017

Putri, Noventia Karina. (2015). Anteseden Minat Loyalitas. Diponegoro Journal of Management Vol.4 No.2. Semarang: Undip.

Sabran. (2012). Prinsip-Prinsip Pemasaran. Edisi 13. Jakarta: Penerbit Erlangga.

Sasongko, Felita dan Hartono Subagio. (2013). Pengaruh Kualitas Pelayanan terhadap Kepuasan Pelanggan pada Restoran Ayam Penyet Ria. Jurnal Manajemen Pemasaran Petra Vol.1 No.2 1-7 Surabaya. http://studentjournal.petra.ac.id/ind ex.php/manajemenpemasaran/artic le/view/519 diakses 16 Juli 2017.

Situmeang, Lina Sari. (2017). Pengaruh Kualitas Pelayanan, Harga dan Lokasi terhadap Kepuasan Konsumen pada Rumah Makan Istana Hot Plate Medan. Skripsi. UINSU. http://repository.uinsu.ac.id/3127/1/S kripsi.pdf

Sodexo.co.id (2019). Kepuasan Pelanggan: Definisi dan Faktor Pendukungnya. Artikel. https://Www.sodexo.co.id diakses 31 Juli 2019.

Sugiyono. (2017). Metode Penelitian Kuantitatif, Kualitatif, dan R\&D. Bandung: CV Alfabeta.

Sulistyawati, Ni Made Arie. (2015). Pengaruh Kualitas Pelayanan terhadap Kepuasan Pelanggan Restoran Indus Ubut Gianyar Bali. E-Jurnal Manajemen Vol. 4 No.8 Tahun 2015. Bali: FE Udayana.

Suwarman, Ujang. (2015). Perilaku Konsumen Teori Penerapannya dalam Pemasaran. Edisi Kedua. Cetakan Ketiga. Bogor: Ghalia Indonesia.

Suwithi dan Anwar. (2013). Manajemen Pemasaran Dasar Konsep dan Strategi. Cetakan Ketiga. Jakarta: Rajawali. 
Safrizal. (2015). Pengaruh Harga dan Kualitas Pelayanan terhadap Kepuasan Konsumen pada Restoran Ayam Penyet Pak Ulis di Kota Langsa. Jurnal Manajemen dan Kevangan Unsam, Vol.4 No.1 Mei 2015.

Tjiptono, Fandy (2016). Service, Quality \& Satisfaction. Yogyakarta: Andi

Wahyudi, Muhammad. (2018). Pengaruh Harga, Lokasi, Suasana dan Kualitas Produk terhadap Kepuasan Pelanggan pada Rumah Makan Lele Kepruk. UIN Raden Fatah Palembang.

http://eprints.radenfatah.ac.id
Widyandani, Estri, (2017) Pengaruh Store Atmosphere terhadap Kepuasan Konsumen Restoran Taman Koleksi Bogor. Skripsi. Bogor: Institut Pertanian Bogor.

Wijaya, Cynthia Violita. (2017). Pengaruh Harga, Kualitas Pelayanan dan Kualitas Produk terhadap Kepuasan Konsumen Depot Madiun Masakan Khas Bu Rudy. Jurnal Agora Vol.5 No.1 2017. Univ. Kristen Petra Surabaya. 